cæcum, and in this region there was well-marked tenderness. After being put to bed and treated with hot bottles, poultices, etc., he quir.kly recovered, but some tenderness over the cæcum remained for a day or two. There was no rise of temperature. He left the hospital in four days, well but very weak.

The two hospital cases were very alarming, and as collapsed as though they had been violently kicked over the solar plexus; but in all the abdominal pain was a marked precurror of the attack, and the collapse its principal feature; while the severe depression that followed was common to all the four cases, though only in two of them was there any evidence of the bronchial irritation from which so many of our influenza patients have suffered.

These cases do, I think, furnish additional evidence that, as Dr. Graves of Dublin and Dr. Blakiston of Birmingham affirmed long ago, influenza is an affection of the nervous system, with its concomitant derangements in the organs of digestion, circulation, etc., while the seat of incidence of the poison may be determined by at present unknown causes.

\section{INFLUENZA IN NORTH LINCOLNSHIRE.}

BY T. B. FRANKLIN EMINSON, M.R.C.S., scotter.

THE prevailing epidemic is now on the wane in the northern parts of Lindsey. The villages in the extreme north were attacked at the end of March almost simultaneously with Yorkshire, and the epidemic rapidly spread southwards, attacking first isolated houses, particularly those in exposed situations, then entering the villages.

The rainfall in February was almost nil, and the winds during March, April, and May, have been north and east, rarely staying in any other quarter for more than a few hours. Early in the epidemic men rather than women were seized; children have suffered more generally than in the epidemic of 1890 , and in them gastric symptoms have been a marked feature.

The severity and suddenness of incidence varied much in difterent villages. In two-Northorpe and Blyton-standing on the slope of high ground and exposed on the north or east, the epidemic came upon the people suddenly, a large proportion being attacked within a few days. This village (Scotter) on the other hand, lying in a sheltered valley, escaped almost entirely for several weeks, and the attack has been more gradual. The fatality has varied much, some villages having had many deaths, others none. Scotter village has suffered severely, notwithstanding that as a rule the uncomplicated attacks have been mild, while the outlying hamlets of the parish have had no fatal case. The parish contains by this year's census 1,099 inhabitants, about 700 in the village and 399 in surrounding hamlets and farms. In May there were 7 deaths in Scotter, equalling a death-rate of 120 per 1,000 , while in the outlying hamlets there has been 1 death (phthisis), giving a death-rate of about 30 per 1,000. Five of these 7 deaths in Scotter have been from pneumonia secondary to influenza, a death-rate of 85.7 per 1,000 from this disease alone. There has been 1 recovery in May, a woman at the sixth or seventh month of pregnancy. She had acute pneumonia of the left apex, accompanying influenza; labour then came on, and crisis followed in four days, but this was succeeded by renewed fever and dry pleurisy. Pneumonia has thus been the ordinary fatal complication, accompanied usually by pleurisy. Many favourable cases of simple pleurisy have been seen. Slight bronchitis has been exceedingly common.

The relationship between influenza and pneumonia must be close. Many of my patients and others believe the present epidemic to be the same disease as the "pleuropneumonic fever," so fearfully fatal in this village last year, and reported on by Dr. Parsons. At present I neither accept nor reject this view, but cannot help noticing the remarkable likeness between the mild non-pneumonic attacks in children which accompanied the pleuro-pneumonic fever of last year and the gastric form of influenza commonly seen this year. In order to entertain the notion of the identity of influenza with this local pneumonia, it is necessary to sup- pose that under some circumstances the influenzal poison can change its habitat from the atmosphere to polluted soils and sewers, for it is now beyond reasonable doubt that the outbreak of pneumonia at Scotter in 1890 was chiefly due to sewer emanations. Yet this outbreak followed close upon the heels of the influenza of 1890, and with the present year's epidemic we have a pneumonia of the same appalling fatality.

\section{CASES OF MEDICO-LEGAL INTEREST. ${ }^{1}$}

By H. NELSON HARDY, F.R.C.S.ED.,

Vice-President Metropolitan Police Surgeons' Association.

In recording these cases I have restricted myself to those which have come before me during the seven years that I have held office as divisional surgeon of the Metropolitan Police, though not altogether to those which have come before me in that capacity. My friend and colleague, Dr. Forsyth, having dealt exhaustively with the subject of drunkenness, I make no reference here to cases of that description, although it is a subject which engrosses a good deal of our attention when called to police stations.

\section{INFANTICIDE.}

Infanticide is a crime which seems to me to be lamentably frequent, and-owing probably in part to the disinclination of coroners to pay for medical evidence at inquests upon these cases-one which is but rarely traced home to its perpetrator. During the whole seven years, out of a number of cases of infanticide to which $I$ have been called at East and West Dulwich stations, I have only, I find, in one case made a post-mortem examination or given evidence at an inquest on a body of a newly-born infant, and my usual record of these cases is as follows: Sent for on such a date at such an hour to - - Police Station to see body of newly-born (male or female) child; cord had (or had not) been tied; wrapped up in paper (or other) parcel, with portion of linen or other garment (if present), and whether any initials or marks on them. As a rule I never hear anything more of the case.

In the solitary case in which a necropsy was ordered, which happened in April, 1885, the body of a female infant was found in a bag wrapped in a child's cape. From the navel having quite healed I came to the conclusion that the child had lived for at least a week, and, from the fact that decomposition had commenced-the weather being cold-that it had probably been dead three or four days. The body was found to be very badly nourished, weighing only 6 lbs. 2 ozs., though its length was 21 inches. There was a total absence of fat subcutaneously and around the internal organs; not a particle of food in the stomach or bowels. Bruises were found on the head and a clot of blood beneath the right temporal bone, which seemed to indicate that, not content with the slow process of starving, other means had been taken to hasten the child's death. An open verdict was returned and there the matter ended.

I have never happened to see the curious mummification of the cord which my friend, Mr. Lowndes, ${ }^{2}$ police surgeon for Liverpool, has described, and of which he has only seen one example in twenty years. He regards it as positive evidence that the child has lived, differing in this from some well-known authorities.

\section{SUICIDE.}

Cases of suicidal tendency or attempted suicide require much watchful and active treatment, and it is seldom, I think, that we are able to record one which comes so near a cure as the following: In 1885 an officer in one of Her Majesty's services was present when a person attempted to cut his throat, and in wresting the knife out of the would-be suicide's hand he cut his own fingers, and thought that some of the other man's blood got into the cuts. A week later he came to me saying he felt very depressed, and that sometimes it seemed as if he too must cut his throat. I made him take

1 Read before the Metropolitan Police Surgeons' Association. ${ }^{2}$ Extraordinary Case of Infanticide: Mummification of the Umbilical Cord. By Fredk. W. Lowndes, M.R.C.S., Surgeon to Liverpool Police. (Pamphlet). 